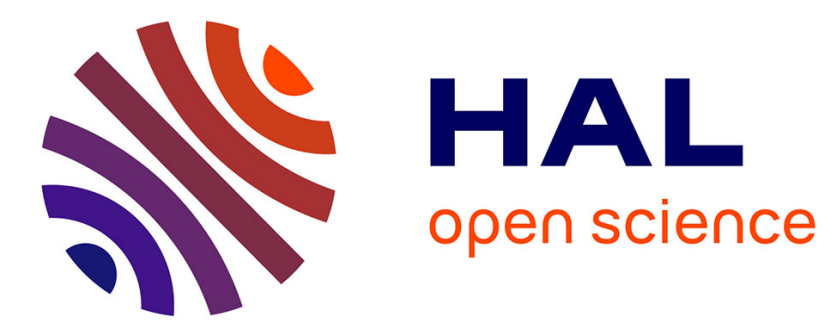

\title{
The Cosmed K4 telemetry system as an accurate device for oxygen uptake measurements during exercise
}

\author{
Christophe Hausswirth, André-Xavier Bigard, Jean-Michel Le Chevalier
}

\section{To cite this version:}

Christophe Hausswirth, André-Xavier Bigard, Jean-Michel Le Chevalier. The Cosmed K4 telemetry system as an accurate device for oxygen uptake measurements during exercise. International Journal of Sports Medicine, 1997, 18 (6), pp.449 - 453. hal-01781757

\section{HAL Id: hal-01781757 \\ https://hal-insep.archives-ouvertes.fr/hal-01781757}

Submitted on 30 Apr 2018

HAL is a multi-disciplinary open access archive for the deposit and dissemination of scientific research documents, whether they are published or not. The documents may come from teaching and research institutions in France or abroad, or from public or private research centers.
L'archive ouverte pluridisciplinaire HAL, est destinée au dépôt et à la diffusion de documents scientifiques de niveau recherche, publiés ou non, émanant des établissements d'enseignement et de recherche français ou étrangers, des laboratoires publics ou privés. 


\title{
The Cosmed K4 telemetry system as an accurate device for oxygen uptake measurements during exercise
}

\author{
C. Hausswirth $^{1}$, A. X. Bigard $^{2}$, J. M. Le Chevalier ${ }^{1}$ \\ ${ }^{1}$ Laboratoire de Biomécanique et de Physiologie, Institut National du Sport et de l'Education Physique, Paris, France \\ ${ }^{2}$ Départment de Physiologie Systémique, Centre d'Etudes et de Recherches de Médicine Aérospatiale, Brétigny sur Orge, France
}

Corresponding Author: C. Hausswirth, Institut National du Sport et de l'Education Physique, Laboratoire de biomécanique et de physiologie 11, avenue du Tremblay 75012 Paris France

The purpose of this study was to test the accuracy of oxygen uptake $\left(\mathrm{VO}_{2}\right)$ measurements using the Cosmed K4 portable telemetry system. This system of higher technology than the original Cosmed K2 device, contains a $\mathrm{CO}_{2}$ electrode allowing measurements alternatively by either the Cosmed $\mathrm{K} 4$ system (K4) or the CPX Medical Graphics (CPX) during a maximum oxygen uptake $\left(\mathrm{VO}_{2} \mathrm{max}\right)$ ergocycle test, at rest and during several submaximal exercices $(25,50$ and $75 \%$ of maximal work rate) in seven subjects. Heart rate values were comparable for exercise at the same work stage during gas collection using the two systems, indicating that the physiological stresses were similar. $\mathrm{The}^{\mathrm{VO}} \mathrm{V}_{2}$ values did not significantly differ at rest $\left(4.40 \pm 0.83 \mathrm{vs} 4.16 \pm 0.58 \mathrm{ml} \cdot \mathrm{min}^{-1} \mathrm{~kg}^{-1}\right)$, at $25 \% \mathrm{Wmax}(20.97 \pm 1.31 \mathrm{vs}$ $\left.21.32 \pm 2.54 \mathrm{ml} \cdot \mathrm{min}^{-1} \bullet \mathrm{kg}^{-1}\right)$, at $50 \% \operatorname{Wmax}\left(33.32 \pm 3.92\right.$ vs $\left.33.50 \pm 3.51 \mathrm{ml} \cdot \mathrm{min}^{-1} \cdot \mathrm{kg}^{-1}\right)$, at $75 \%$ Wmax (47.01 $\left.\pm 7.51 \mathrm{vs} 47.49 \pm 7.11 \mathrm{ml} \bullet \mathrm{min}^{-1} . \mathrm{kg}^{-1}\right)$ and at maximal intensities $(62.07 \pm 8.48 \mathrm{vs} 62.84$ $\pm 11.31 \mathrm{ml} \cdot \mathrm{min}^{-1} \cdot \mathrm{kg}^{-1}$ ) using K4 and CPX devices, respectively. The results of this study indicated that the K4 system was accurate for all oxygen uptake measurements from rest to maximum exercise levels. Key words: Validity, maximum oxygen uptake, respiratory exchange ratio, ventilation, respiratory rate

\section{Introduction}

Oxygen uptake $\left(\mathrm{VO}_{2}\right)$ is often measured to determine the metabolic cost of physical activities in the field. This metabolic cost, defined as the steady-state aerobic demand for a given intensity, has been identified as an important factor to direct athletes in managing their training programs $(7,12)$. Until recently, $\mathrm{VO}_{2}$ was measured by the Douglas bag method which involves the use of voluminous and bulky apparatus. As a result it was difficult to measure $\mathrm{VO}_{2}$ during physical exercise when not using a portable telemetric system.

Previous studies were conducted in order to evaluate the accuracy of some telemetric systems which measured $\mathrm{VO}_{2}(2,3,8)$. A thorough search of the literature revealed some interest for the $\mathrm{K} 2 \mathrm{Cosmed}$ apparatus $(3,9,10,11)$. However, since the $\mathrm{K} 2$ Cosmed system does not contain a $\mathrm{CO}_{2}$ electrode, it is assumed that the respiratory exchange ratio (RER) is equal to 1.00 . The K2 Cosmed system significantly underestimated $\mathrm{VO}_{2}$ measurements at low workloads in comparison with $\mathrm{VO}_{2}$ obtained from a standard metabolic cart (11).

A newer model of the K2 Cosmed apparatus has been developed. This system (K4 Cosmed, Roma Italy) contains a $\mathrm{CO}_{2}$ electrode allowing direct measurements of the RER at rest or during exercise. It is much reduced in size and mass compared with the K2 telemetric system. However, before its implementation in the field, the accuracy of this telemetric system had to be tested.

Thus, the purpose of this study was to test the validity and the accuracy of the K4 Cosmed telemetric system for measuring oxygen uptake, minute ventilation, respiratory rate and respiratory exchange ratio in a laboratory exercise test at maximum and submaximum intensities.

\section{Material and Methods}

Subjects. Seven healthy, well-motivated male subjects, volunteered to participate in this study after 
they were informed of the nature and possible inconveniences associated with the experiment. The subjects were familiar with all testing procedures and gave their written informed consent before participation. Subject's mean $( \pm \mathrm{SD})$ age, weight and height were $32.2 \pm 6.9 \mathrm{yrs}, 71.2 \pm 5.4 \mathrm{~kg}, 177.5 \pm$ $5.2 \mathrm{~cm}$, respectively. Two of the subjects were endurance trained triathletes, who trained $9-10$ times per week. The five other subjects were physically active in a variety of sports (cycling and running) 3-4 times per week.

Maximum oxygen uptake evaluation. After a 48 hour restriction of strenuous physical activity, the subjects completed two incremental, continuous maximum bicycle ergometer exercise tests at three day interval, using either a metabolic measurement cart (type CPX, Medical Graphics, Saint-Paul, Minnesota, USA), (CPX), or the telemetric measurement system (type Cosmed K4, Roma, Italy), (K4). We used an electromagnetically braked bicycle ergometer (Excalibur, Lode, Groningen, The Netherlands) in which adjustment of the load was rate-independent. The copper disk is driven by the axle by a special chain and a gear belt transmission. The test began with a warm-up at $100 \mathrm{~W}$ for 6 minutes and the workload was increased by $25 \mathrm{~W}$ every 2 minutes until volitional fatigue. During the two incremental exercises, oxygen uptake $\left(\mathrm{VO}_{2}\right)$, car-bon dioxide output $\left(\mathrm{VCO}_{2}\right)$, minute ventilation (VE), respiratory rate (RR) and respiratory exchange ratio (RER) were continuously measured every 15 seconds using either CPX Medical Graphics (CPX) or the Cosmed K4 system (K4): the order for the use of the $\mathrm{K} 4$ of the $\mathrm{CPX}$ in the maximal exercise tests was randomized. A small connection was adapted on the soft face mask for the attachement of the low-resistance respiratory value directing the exhaled air to either the metabolic measurement cart of the turbine flowmeter (Cosmed $\mathrm{K} 4$ system). The maximum oxygen uptake $\left(\mathrm{VO}_{2} \mathrm{max}\right)$ was the average of the last three highest consecutive $\mathrm{VO}_{2}$ values recorded. The criteria used for $\mathrm{VO}_{2} \max$ were those previoulsy described (1). This always occurred during the next-to-last or last work rate, thus we are confident that we got a true $\mathrm{VO}_{2} \mathrm{max}$. The maximum work rate $(\max )$ was the highest work rate completed for 2 minutes and was measured during both $\mathrm{CPX}$ and $\mathrm{K} 4$ exercises.

Submaximum steady-rate tests. All subjects refrained from any recreational activity 24 hours before testing. They remained at rest on the bicycle ergometer for 12 minutes and exercised for 12 minutes at $25 \%, 12$ minutes at 50\% and 12 minutes at $75 \%$ Wmax. Pedalling cadence was freely chosen by the subjects at the beginning of each work rate and was maintained during each submaximum test. All testing sessions were completed at the same time of day for each subject after eating a standard lunch ( 3 hours postabsorptive). The differences observed in HR were evaluated using a. cardiofrequency meter (BHL-6000, Baumann-Haldi SA, Fleurier, Switzerland). The interval of calculation for $\mathrm{VO}_{2}$ was set at 15 seconds. To collect the exhaled air, we reproduced the experimental procedure design by Bigard and Guezennec (3). A small connecter, which was mounted on a soft face mask, allowed collection of the exhaled air with only one system (face mask) and analysis with either K4 or CPX without stopping the bicycle test. The resting measurements and each submaximum exercise lasted 12 minutes. With this alternated and repeated experimental procedure, two sets of data using each instrumentation were available. The two systems were used in a randomly assigned order.

Metabolic measurements. The Cosmed K4 telemetry system has not been previously described but has some identical characteristics compared with the K2 system widely described $(5,8,11)$. The K4 system is composed of a soft face mask to sample exhaled air, a sensor system to measure ventilation, oxygen and carbon dioxide concentrations in the expired air, allowing RER calculation. The respiratory flow is measured by a turbine (diameter of $28 \mathrm{~mm}$ versus $2 \mathrm{~mm}$ for the K2 system) fixed to the face mask. This flow sets in motion the mobile rotor blade which has a low mass and extremely reduced inertia. The rotation of the turbine is measured by an opto-electronic system that counts the revolutions per second. The system has also a transmitter unit, an electrode to pick-up heart rate and a Ni-Cd rechargeable battery (lasting about 1 hour) all attached to a chest harness, and a receiver unit. The flowmeter measures the airflow rate, calculates the volume of air expired per minute and counts the number of expiratory cycles per minute. To measure the concentration of oxygen, the exhaled air moves through a special capillary tube (Permapure) to the transmitter unit that contains a polarographic electrode for measurement the $0_{2}$ fraction in the expired gas $\left(\mathrm{FEO}_{2}\right)$. Oxygen moves through a membrane into an electrolytic solution. The $\mathrm{CO}_{2}$ electrode is an infrared electrode. The $\mathrm{K} 4$ system was calibrated before each experiment according to the manufacturer recommended procedures (Operator Manual of K4 System). The transmitter was turned on for a minimum of 20 minutes before each test. 
The $0_{2}$ and $\mathrm{CO}_{2}$ analysers were calibrated using ambiant air at the beginning of each testing session ( $20.93 \%$ and $0.03 \%$, respectively), and the turbine flowmeter was calibrated using a $3-1$ syringe at the beginning of the study. The $\mathrm{O}_{2}$ and $\mathrm{CO}_{2}$ analyzer are thermostated and compensated for a barometric pressure and environmental humidity variations. Oxygen uptake is calculated according to the following formula:

$$
\dot{\mathrm{VO}}_{2, \mathrm{STDP}}-\dot{\mathrm{V}}_{\mathrm{E} . \mathrm{STDP}} \times\left\{\left[1-\frac{\left(\mathrm{F}_{\mathrm{E}} \mathrm{O}_{2}+\mathrm{F}_{\mathrm{E}} \mathrm{CO}_{2}\right)}{1-\mathrm{F}_{\mathrm{i}} \mathrm{O}_{2}} \times \mathrm{F}_{\mathrm{i}} \mathrm{O}_{2}\right] \quad \mathrm{F}_{\mathrm{E}} \mathrm{O}_{2}\right\}
$$

$\mathrm{VE}=$ minute exhaled volume,

$\mathrm{F}_{\mathrm{i}} \mathrm{O}_{2}=$ calibration value 02

$\mathrm{F}_{\mathrm{E}} \mathrm{O}_{2}=$ fractional concentration of oxygen in the expired air

The sampling and the printing of the most significant parameters, i.e. $\mathrm{VO}_{2}, \mathrm{VCO}_{2}, \mathrm{VE}$, RER and $\mathrm{HR}$ were carried out at 15 second intervals. The radio transmission range in an open field is about $3 \mathrm{~km}$ using a small $30 \mathrm{~cm}$ long receiving antenna; for a wider range, special antenna can be used. The total weight carried by the subject is about $800 \mathrm{~g}$. Furthermore, the apparatus includes a communication interface to download all recorded parameters onto a personal computer. Data were collected and treated on the software "K4 for Windows".

The CPX analyser is constituted with two modules: a flowmeter module which measures ventilatory parameters and a gas module which measures $\mathrm{FE}_{2}$, and $\mathrm{FECO}_{2}$. Each subject wore the Cosmed $\mathrm{K} 4$ 's face mask and inhaled ambiant air through one Bide of a low-resistance three-way valve (Hans Rudolph, Inc., Kansas City, MO, USA). Expired $\mathrm{O}_{2}$ and $\mathrm{CO}_{2}$ fractions were measured from a sampling port in the mouthpiece connected by way of a capillary sampling tube to an $0_{2}$ analyser constituted by a zirconium cell and a $\mathrm{CO}_{2}$ analyser using an infrared electrode. The temperature of the samples and a barometer reading were taken. Before each submaximal and maximal test, both gas analyzers were calibrated with reference gases according to the manufacturer's recommendations, at $\mathrm{O}_{2}$ and $\mathrm{CO}_{2}$, concentrations of 12.01 and $5.01 \%$, respectively. On-line computation was obtained using customized software for V02, VE, RR and RER determination. The interval between calculations of these parameters was set at 15 seconds.

\section{Data and statistical analysis}

1.During the two maximal tests, each subject's values for $\mathrm{VO}_{2}, \mathrm{VCO}_{2}, \mathrm{VE}, \mathrm{RR}$, RER and HR were evaluated using the $\mathrm{K} 4$ and the $\mathrm{CPX}$ system. The average of the last three values $\left(\mathrm{VO}_{2} \mathrm{max}, \mathrm{VCO}_{2} \max\right.$, V Emax, RRmax, RERmax and HRmax) recorded were used in the statistical analysis. Differences in the dependent variables resulting from the type of measurement system (K4, CPX) were studied using a Student's $t$-test for paired samples. Statistical significance was accepted at $P<0.05$.

2.During the submaximum testing sessions, two series of 3 min data were available for each system of measurement. The first 2 minutes of data collection were eliminated at rest and during each work load. When subjects pedalled at $75 \% \mathrm{Wmax}$, the first 3 minutes of data collection were similarly eliminated. The statistical comparisons between $\mathrm{VO}_{2}, \mathrm{VCO}_{2}, \mathrm{~V}$ E, RR, RER, and $\mathrm{HR}$ were performed using an analysis of variance (ANOVA) for repeated measures. The main effects of "workload" (x 4), "subjects" (x 7), and "system" (x 2) were evaluated on all variables. Results are expressed as mean \pm standard deviation and significance was set a $P<0.05$. The correlation coefficient (r) was calculated for $\mathrm{VO}_{2}$, $\mathrm{VCO}_{2}, \mathrm{VE}, \mathrm{RR}$ and RER values, in order to determine the strength of the relation between measurements made by the different testing methods. Furthermore, the accuracy of the Cosmed K4 system of $\mathrm{VO}_{2}$ measurements was determined according to the method of Bland and Altman (4). For this analysis, the measuring agreement of the $\mathrm{K} 4$ device for $\mathrm{VO}_{2}$ calculation was estimated in indicating the differences in $\mathrm{VO}_{2}$ between the two methods against their mean. The mean of the differences represented the bias between the two systems of measurement. This value plus and minus two standard 
deviations represented the limits of agreement for $\mathrm{VO}_{2}$ measurement using the Cosmed $\mathrm{K} 4$ system. The data were presented graphically comparing the difference between the methods versus their average value for $\mathrm{VO}_{2}$.

\section{Results}

Heart rate (HR) values were unaffected by the system of measurement $(P=0.87)$. As indicated in Tables 1 and 2, HR was almost identical during gas collection with either the K4 or the CPX at rest and for bicycle exercices $(25 \% \mathrm{Wmax}, 50 \% \mathrm{Wmax}, 75 \% \mathrm{Wmax}$ and Wmax). HR values were similar for each level using the two systems with repeated and alternated measures of respiratory parameters.

Maximal oxygen uptake $\left(\mathrm{VO}_{2} \max \right)$, maximal carbon dioxide output $\left(\mathrm{VCO}_{2} \mathrm{max}\right)$, maximal minute ventilation (VE max), maximal respiratory rate (RRmax) and maximal respiratory exchange ratio (RERmax) values for the K4 and the CPX devices are shown in Table 1. These measurements were unaffected by the system $(\mathrm{P}=0.89, \mathrm{P}=0.84, \mathrm{P}=0.68, \mathrm{P}=0.91, \mathrm{P}=0.75$, respectively) (Table 1$)$.

V02, VCO2, VE, RR and RER measurements increased with the workload $(\mathrm{P}<0.001)$ and were affected by an interindividual variability $(\mathrm{F}=113.7 ; \mathrm{P}<0.001)$. The analysis of variance on VE measurements indicated no significant effect of the system $(P=0.14)$ (Table 1) (Fig. 1 a). In addition, the measurements of VE using the K4 or the CPX systems were highly correlated $\left(\mathrm{r}^{2}=0.995, P<\right.$ $0.001)$. The $95 \%$ confidence interval for the experimental lines covered the entire range of VE values.

Mean values of RR were unaffected by the system $(P=0.26)$, (Fig.1 b). Moreover, there was a high correlation between RR results obtained by use of K4 or CPX devices $\left(r^{2}=0.962, P<0.001\right)$.

The mean values of RER obtained during the submaximal exercises using the K4 did not significantly differ from those calculated with the CPX (Fig. 2a).

Correlations between $\mathrm{VO}_{2}$ values measured with the two systems during the four sessions (rest, $25 \%$ Wmax, 50\% Wmax and $75 \% \mathrm{Wmax}$ ) were highly significant $\left(P<0.001, \mathrm{r}^{2}=0.953\right) . \mathrm{VO}_{2}$ values (Fig. 2 b) and $\mathrm{VCO}_{2}$ values (Fig. 3) calculated by the $\mathrm{K} 4$ system did not differ significantly $(P>0.47$ and $P>$ 0.53 , respectively) from those calculated by the CPX device. As shown in Fig. 4, the confidence interval for the bias (i.e. mean difference between the two systems) was 3.13 to $-3.51 \cdot \mathrm{min}^{-1} \cdot \mathrm{kg}^{-1}$. Almost all the individual values were within the limits of agreement, and for each of the exercice intensities, only one individual value was outside the limits of agreement at $25 \%$ Wmax.

\section{Discussion}

The aim of this investigation was to test a new telemetric system (type Cosmed K4) which includes the measurement of the fractional concentration of carbon dioxide in the expired gas ( $\mathrm{FeCO} 2)$. The main interest of our study was to compare the validity and accuracy of $\mathrm{VO}_{2}$ measurements at whatever value of the respiratory gas exchange ratio (range $0.7-1.2$ ), by use of either the Cosmed $\mathrm{K} 4$ system or the $\mathrm{CPX}$ Medical Graphics system. One interesting finding of this study indicated that $\mathrm{VO}_{2}$ values calculated using the $\mathrm{K} 4$ system were not statistically different from $\mathrm{VO}_{2}$ values obtained with the CPX system. The results showed a validity of the $\mathrm{K} 4$ system for $\mathrm{VO}_{2}$ measurements in the same subjects during both submaximal and maximal exercises. A previous study (13) found some difference in $\mathrm{VO}_{2}$ values obtained during two maximal exercise tests using either the Cosmed $\mathrm{K} 2$ system and the conventional Douglas bag method $\left(3.57 \pm 0.76\right.$ vs $3.69 \pm 0.761 . \mathrm{min}^{-1}$, respectively). The same difference was also recorded at low running speed ( $2.11 \pm 0.43$ vs $2.21 \pm 0.441 . \mathrm{min}^{-1}$, respectively).

Accuracy and validity of oxygen uptake and minute ventilation measurements show that the day-to-day variability in subject's response should be closely noted (10). In order to reduce differences resulting from the order of the use of the measurement systems, the two devices were used in a randomly assigned order during the 3 submaximal exercises (3). With this alternated and repeated experimental procedure, two sets of data using each instrumentation were available at rest and during the 25 and $50 \%$ Wmax bicycle exercise, and only one segment of data collection was available at $75 \%$ Wmax. 
Moreover, the heart rate recorded at each exercise level was not significantly different between the two maximal tests and between the two systems during the three submaximal testing sessions. This strongly suggests that the amount of work performed during both exhaustive and submaximal exercises was unaffected by the type of device.

As it has been previously reported, the Cosmed K2 system was shown to be valid and reliable for oxygen uptake measurements at both submaximal and maximal intensities $(6,9,10)$. However, Kawakami et al. (9) reported that RER measured by the Douglas bag method at maximal workload did not exceed $0.95 \pm 0.06$. It is clear in this case that the measurement error (assuming RER $=1.00$ ) did not affect the validity of $\mathrm{VO}_{2} \max$ values. Lucia et al. (10) reported that at low-intensity work rates, the RER was less than 1.00 and the $\mathrm{K} 2$ apparatus tended to underestimate $\mathrm{V}_{2}$ values. At maximal workload, mean RER values were 1.21 , corresponding to the values generally recorded when achieved $\mathrm{VO}_{2}$ max. Using the correction factor provided by the manufacturer, it is suggested that when RER is equal to 1.2 , the $\mathrm{K} 2$ apparatus overestimated $\mathrm{VO}_{2} \max$ values by about $4 \%$. DalMonte et al. (6), have previously demonstrated that the difference between fractional concentrations of oxygen in the inspired and expired air $\left(\mathrm{a} \mathrm{FEO}_{2}\right.$ ) was lower at maximal work rate by use of the $\mathrm{K} 2$ system, and then underestimated $\mathrm{VO}_{2}$ values. In addition, when RER was higher than 1.00 , it has been shown that the $\mathrm{K} 2$ system overestimates $\mathrm{VO}_{2}$ values. Thus, correct measurements of $\mathrm{VO}_{2}$ max were expected in this study, in spite of some errors. However, it is clear that accurate measurements of $\mathrm{VO}_{2}$ at high levels of exercise (RER > 1.1) need either VI or $\mathrm{FECO}_{2}$ measurements, in addition to VE and $\mathrm{FECO}_{2}$ data.

The main purpose of the present investigation was to report the first testing procedure of a new telemetric system (Cosmed K4) measuring VE, $\mathrm{FECO}_{2}$ and calculating RER on-line. Summing up, results of this study indicated a great accuracy of the measurements at three work stages $(25,50$ and $75 \%$ Wmax $)$, but also at Wmax $(\mathrm{RER}=1.19)$.

This lightweight and accurate telemetric system enables measurement of energy requirements for maximal or submaximal exercises, in different environmental conditions (laboratory or field-test situations). The continuous recording of $\mathrm{VO}_{2}$ during incremental progressive field tests is possible using the K4 system, in order to determine precisely ventilatory characteristics of each athlete. However, the polarographic electrode of oxygen analysis is very sensitive to temperature variations (5). The temperature at the $\mathrm{O}_{2}$ and $\mathrm{CO}_{2}$ electrodes should be stable prior to calibration. Thus the use of the $\mathrm{K} 4$ de-vice allows us to determine more precisely the energy cost of physical activities, either mild restricting activities (hiking, cycling, tour, walking on uneven field, riding...) or strenuous ones (triathlon, running races, cross-country, skiing...).

From the results of this study, we have tested the validity of a new telemetric system for measuring oxygen uptake during exercise. This new system is practical and useful for oxygen uptake measurements during both submaximal and maximal exercises. Further investigations are needed to test the validity of the K4 system using different modes of exercise and different environmental conditions (low-temperature, wind situation, moderate altitude...).

\section{Acknowledgements}

The authors would like to express their appreciation to J. F. Berthet for his technical assistance, and to Dr. Joussellin and Dr. Vallier for their collaboration. We also thank all the subjects for their support in this project. 


\section{References}

1 Astrand P. O., Ryhming I.: A nomogram for calculation of aerobic capacity (physical fitness) from pulse rate during submaximal work.J Appl Physiol 7: 218 - 222, 1954.

2 Ballai M. A., MacDonald I. A.: An evaluation of the Oxylog as a portable device with which to measure oxygen consumption. Clin Phys Physiol Meas 3: 57 - 65, 1982.

3 Bigard A. C., Guezennec C. Y.. Evaluation of the Cosmed K2 telemetry system during exercise at moderate altitude. Med Sci Sports Exerc 9: 1333 - 1338, 1995.

4 Bland J. M., Altmann D. G.. Statistical methods for assessing agreement between two methods of clinical measurement. Lancet 1: 307-310,1986.

5 Crandall C. G., Taylor S. L, Raven P. B.: Evaluation of the Cosmed K2 portable telemetric oxygen uptake analyser. Med Sci Sports Exerc 26: 108 - 11, 1994.

6 DalMonte A. M., Faina M., Leonardi L M., Todaro A., Guidi G., Pet-relui G.: Maximum oxygen consumption by telemetry. SDS Rivista di Cultura Sportiva 8: 35 - 44, 198.

7 Davis J. A., Convertino V. A.: A comparison of heart rate methods for predicting endurance training intensity. Med Sci Sports Exerc 7: 295 - 298, 1975.

8 Ikegami Y., Hiruta S., Ikegamy H., Miyamura M.: Development of a telemetry system for measuring oxygen uptake during sport activities. Eur J Appl Physiol 57: 622 - 625, 1988.

9 Kawakami Y., Nozaki D., Matsuo A., Fukunaga T.: Reliability of measurement of oxygen uptake by a portable telemetric system. Eur J Appl Physiol 65: 409 -414, 1992.

10 Lucia A., Fleck S. J., Gotshall R. W., Kearney J. T.: Validity and reliability of the Cosmed K2 Instrument. IntJ Sports Med 14: 380-386, 1993.

11 Peel C., Utsey C.: Oxygen comsumption using the K2 telemetry system and a metabolic cart. Med Sci Sports Exerc 25: 396 - 400, 1993.

12 Pollock M. L: The quantification of endurance training programs. In: Wilmore, J. (Ed.): Exercise and Sport Sciences Reviews. Academic Press, New York. 1973, pp 155 -188.

13 Versteeg P. G. A., Kippersluis G. J. A.: Automated systems for measurement of oxygen uptake during exericse testing. Int J Sports Med 10: 107 -112,1989. 
Fig. 1 a Minute ventilation (VE, 1. $\mathrm{min}^{-1}$ ) measured using either the $\mathrm{K} 4$ or the CPX systems, at rest and for each exercise level. Values are means \pm SD. Exercise levels are expressed as a percentage of the maximal work rate (Wmax).

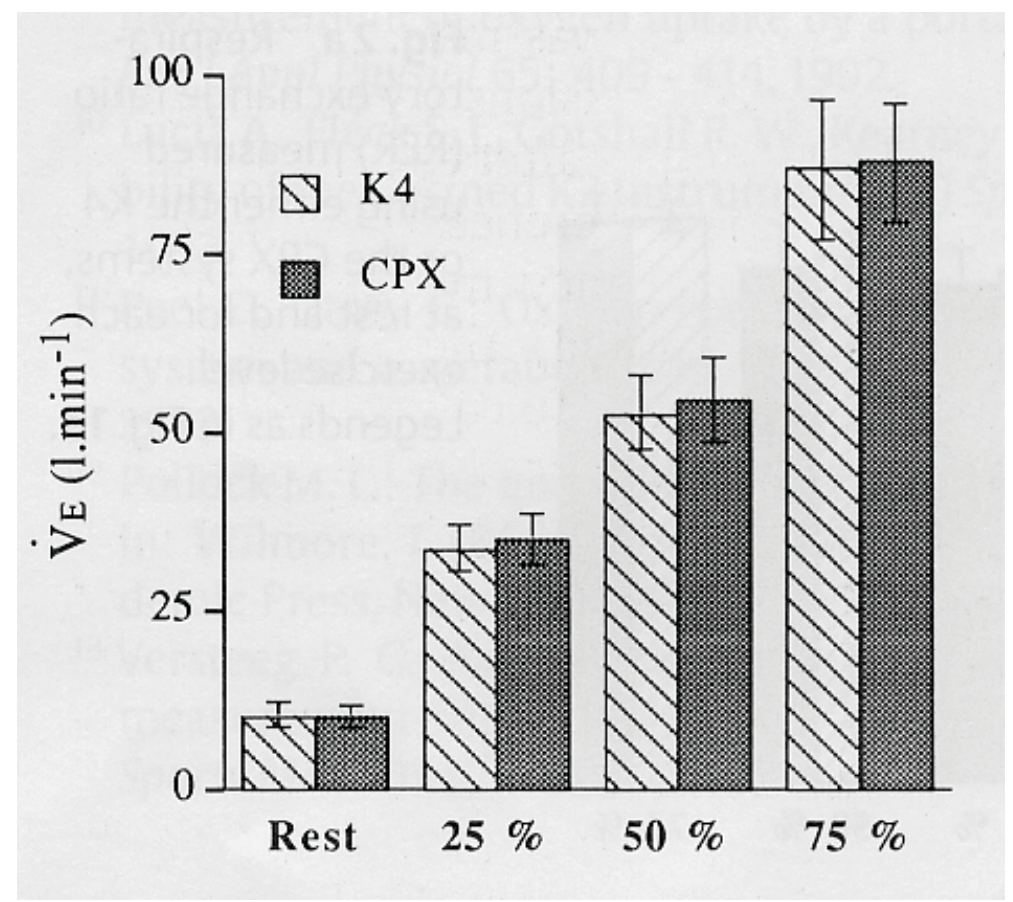

Fig.1 b Respiratory rate $\left(\mathrm{RR}\right.$, breath $\left.\cdot \mathrm{min}^{-1}\right)$ measured using either the $\mathrm{K} 4$ of the CPX systems, at rest and for each exercise level. Legends as in Fig.1 a.

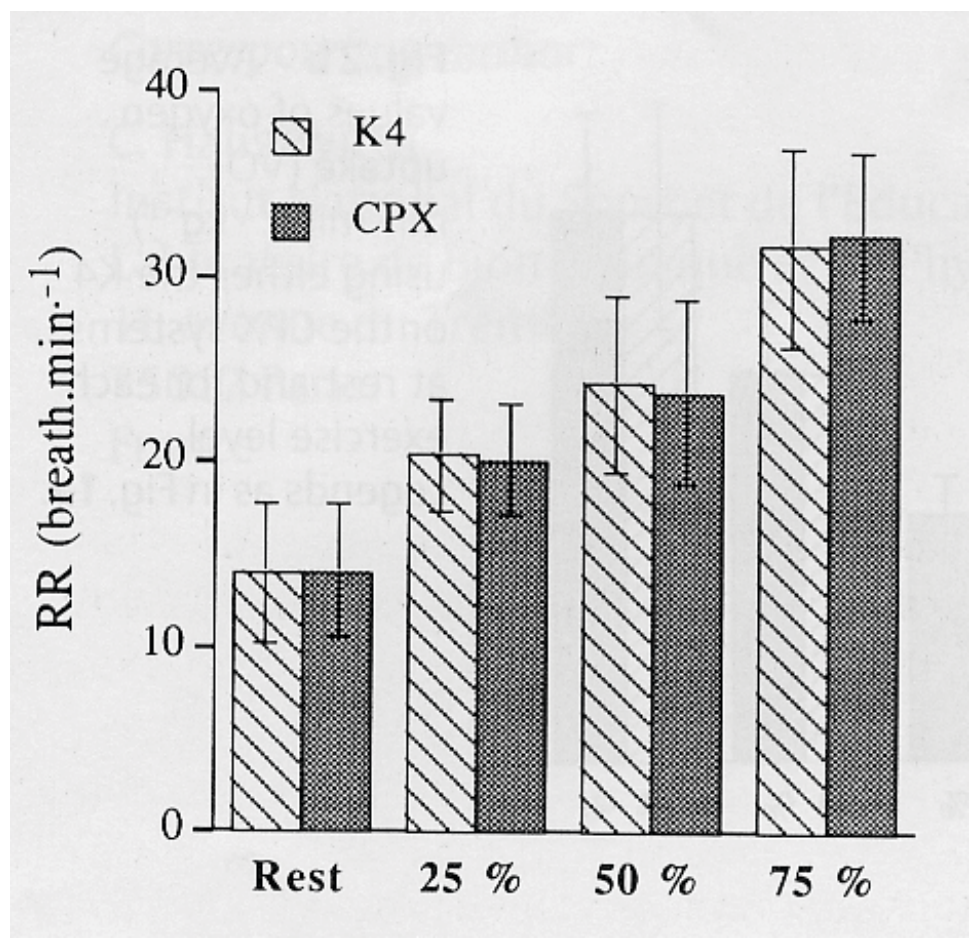


Fig. 2a Respiratory exchange ratio (RER) measured using either the $\mathrm{K} 4$ or the CPX systems, at rest and for each exercise level. Legends as in Fig. 1 a.

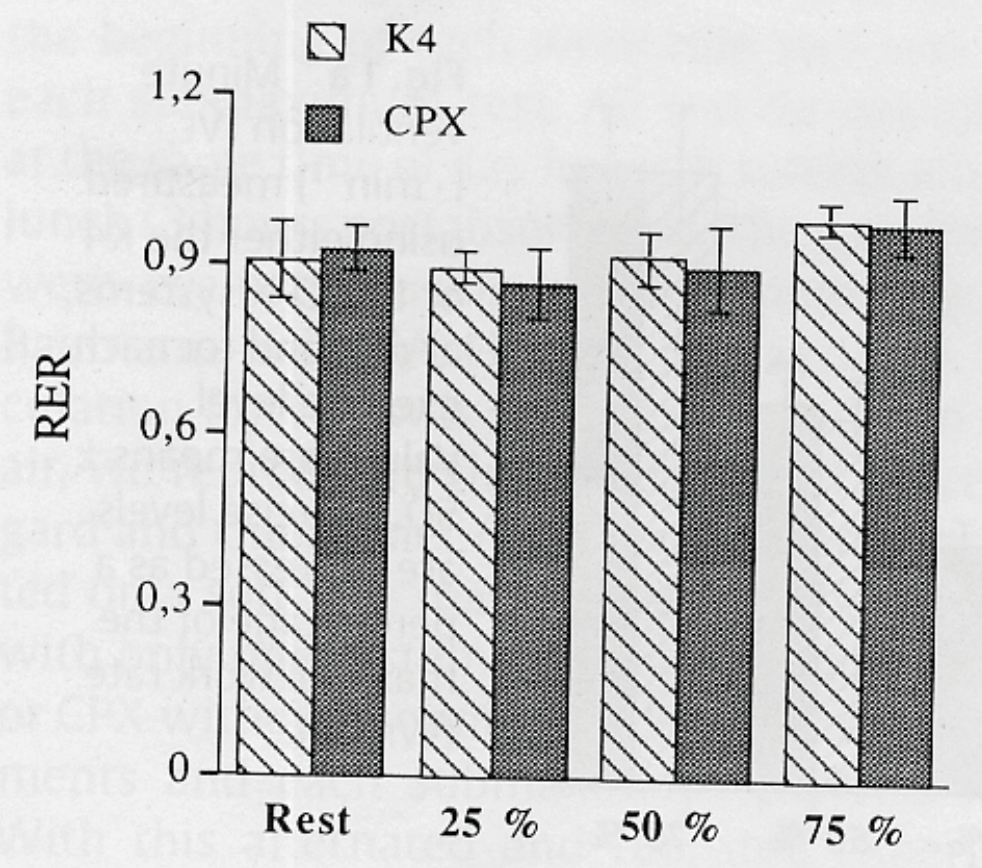

Fig. 2 b Average values of oxygen uptake $\left(\mathrm{VO}_{2}, \mathrm{ml} \cdot \mathrm{min}^{-1} \bullet \mathrm{kg}^{-1}\right)$ using either the $\mathrm{K} 4$ or the $\mathrm{CPX}$ systems, at rest and for each exercise level. Legends as in Fig. 1 a.

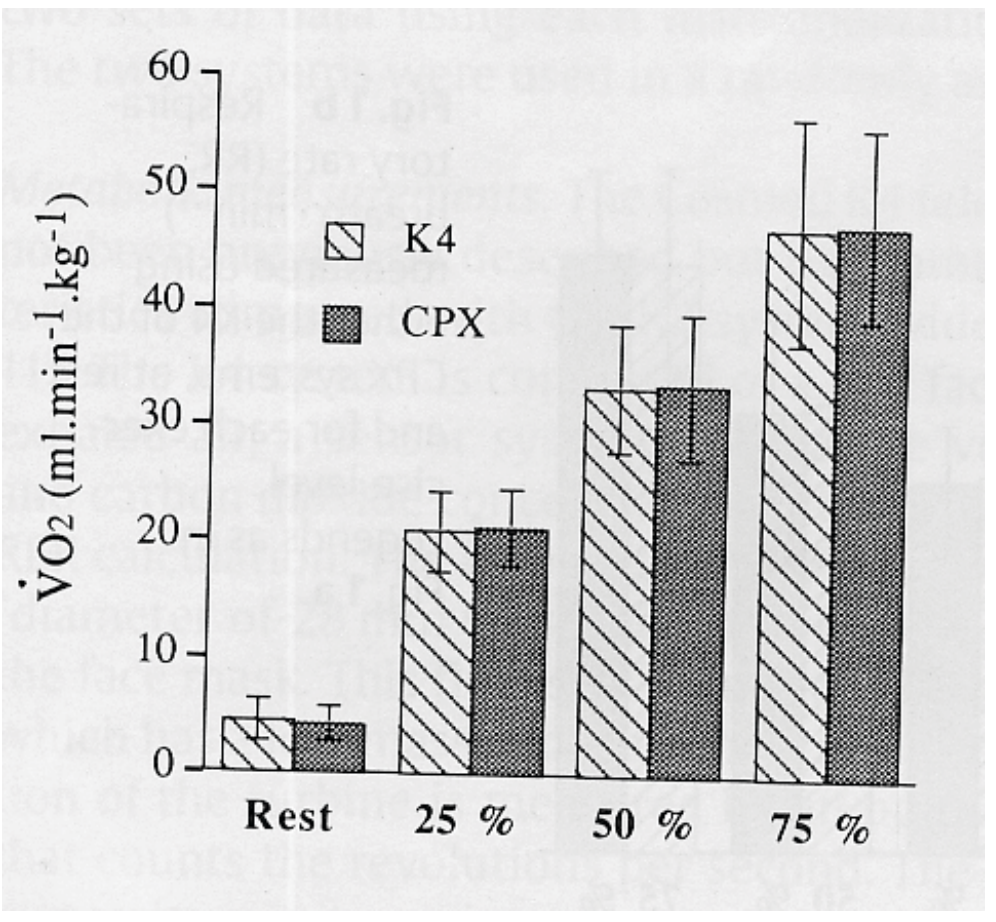


Fig. 3 Average values of carbon dioxide output $\left(\mathrm{VCO}_{2}, \mathrm{ml} \cdot \mathrm{min}^{-1} \cdot \mathrm{kg}^{-1}\right)$ using either the $\mathrm{K} 4$ or the CPX systems, at rest and for each exercise level. Legends as in Fig. 1 a.

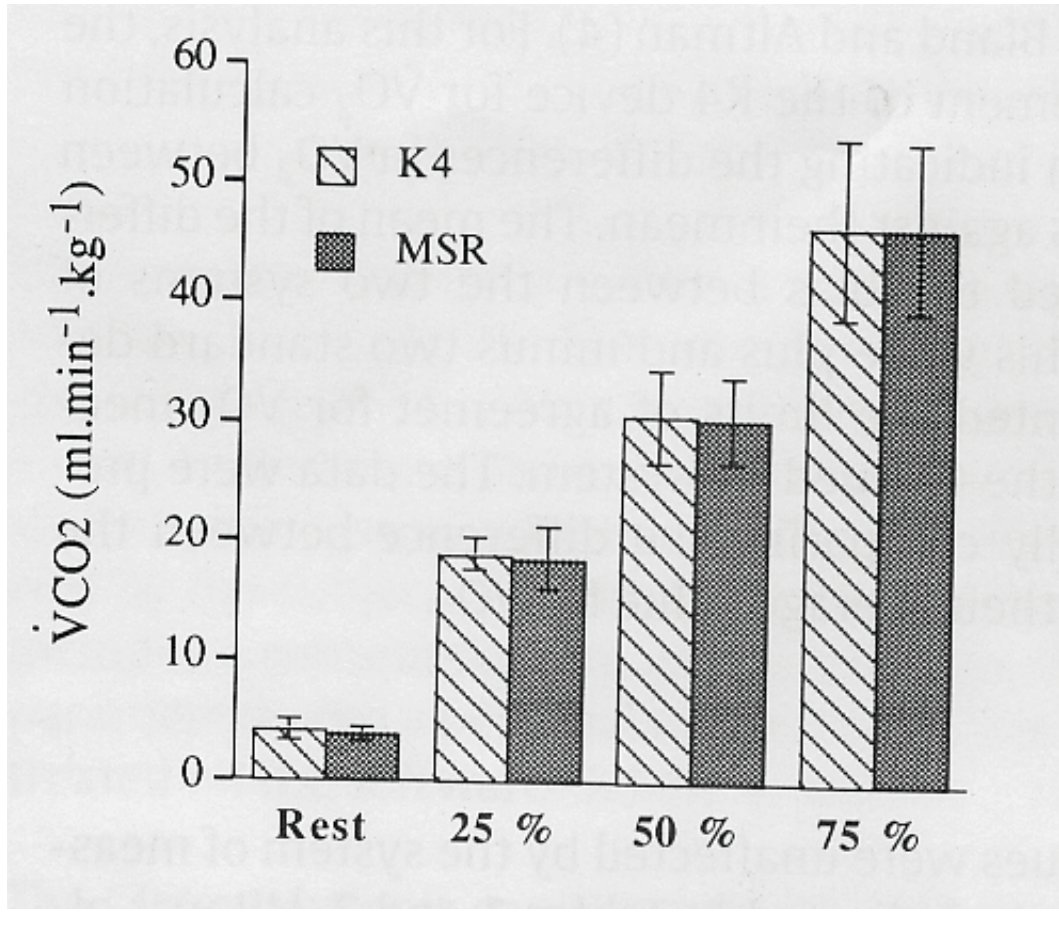

Fig. 4 The calculated bias between the two devices of measurement and the limits of agreement for $\mathrm{VO}_{2}$ measurement using the Cosmed $\mathrm{K} 4$ system: o rest; $\bullet 25 \%$ of maximal work rate (Wmax); $\square 50 \%$ Wmax; 75\% Wmax.

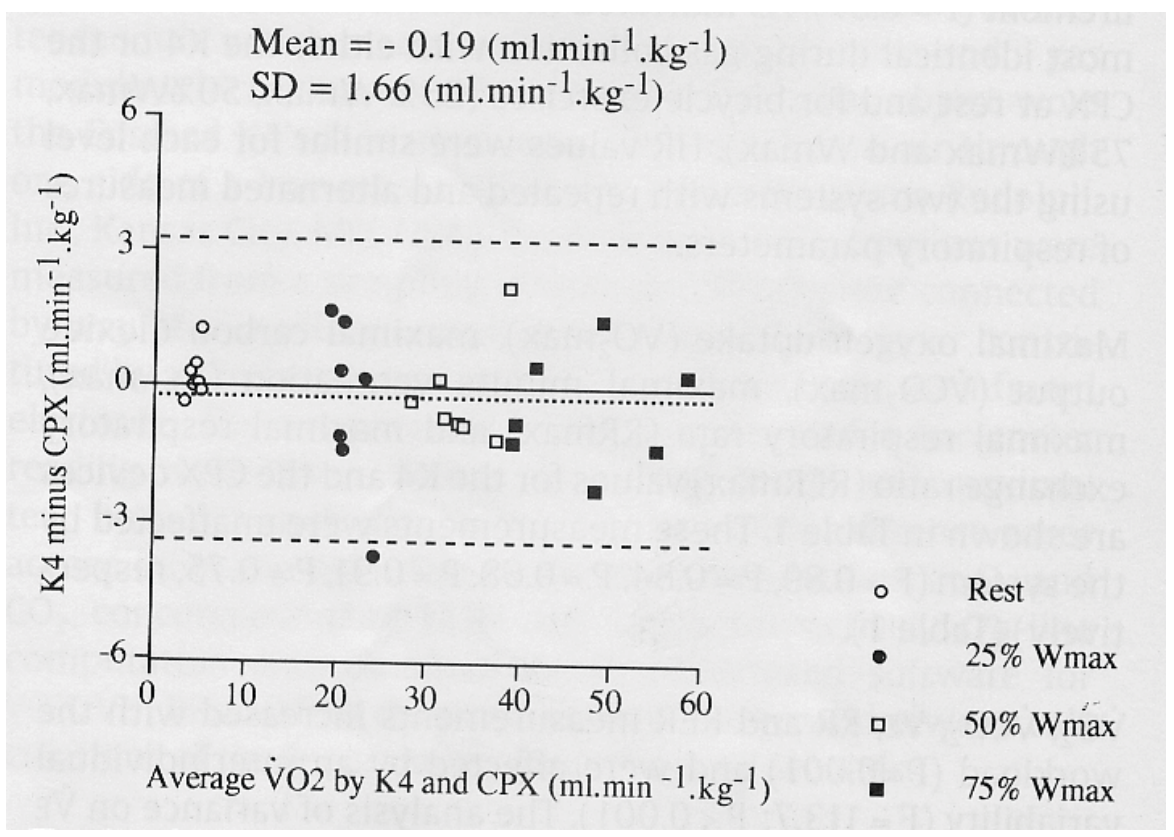


Table 1 Maximal exercise data with incremental protocol. Comparison of K4 and CPX systems.

\begin{tabular}{|l|c|r|}
\hline Parameters & K4 & \multicolumn{1}{c|}{ CPX } \\
& Means \pm SD & Means \pm SD \\
\hline $\mathrm{VO}_{2} \max ,\left(\mathrm{ml} \cdot \mathrm{min}^{-1} \cdot \mathrm{kg}^{-1}\right)$ & $62.07 \pm 8.48$ & $62.84 \pm 11.31$ \\
\hline $\mathrm{VCO}_{2} \mathrm{max},\left(\mathrm{ml} \cdot \mathrm{min}^{-1} \cdot \mathrm{kg}^{-1}\right)$ & $73.85 \pm 9.12$ & $76.65 \pm 11.02$ \\
\hline $\mathrm{VE} \mathrm{max},\left(1 \cdot \mathrm{min}^{-1}\right)$ & $157.41 \pm 25.02$ & $158.42 \pm 25.78$ \\
\hline RRmax, $\left(\right.$ breath $\left.\bullet \mathrm{min}^{-1}\right)$ & $51.28 \pm 9.26$ & $50.85 \pm 8.55$ \\
\hline RERmax & $1.19 \pm 0.06$ & $1.22 \pm 0.04$ \\
\hline Wmax $($ watts $)$ & $339 \pm 35$ & $339 \pm 35$ \\
\hline HRmax, (beat $\left.\cdot \mathrm{min}^{-1}\right)$ & $183 \pm 13.8$ & $184 \pm 14.3$ \\
\hline
\end{tabular}

$\mathrm{VO}_{2} \max =$ maximal oxygen uptake, $\mathrm{VCO}_{2} \max =$ maximal carbon dioxide output, VEmax $=$ maximal minute ventilation, $R R \max =$ maximal respiratory rate, $R E R \max =$ maximal respiratory exchange ratio, $\mathrm{Wmax}=$ maximal work rate, $\mathrm{HRmax}=$ maximal heart rate. No statistical difference has been established.

Table 2 Heart rate (beats $\cdot \min ^{-1}$; mean $\pm \mathrm{SD}$ ) during steady-state exercises.

\begin{tabular}{|l|l|l|}
\hline Exercise level & $\mathrm{K} 4$ & $\mathrm{CPX}$ \\
& Means \pm SD & Means \pm SD \\
\hline Rest & $64 \pm 9.7$ & $67 \pm 10.0$ \\
\hline $25 \% \mathrm{Wmax}$ & $96 \pm 8.9$ & $96+7.4$ \\
\hline $50 \% \mathrm{Wmax}$ & $133 \pm 9.3$ & $134 \pm 8.4$ \\
\hline $75 \% \mathrm{Wmax}$ & $168 \pm 5.5$ & $169 \pm 6.6$ \\
\hline
\end{tabular}

Wmax $=$ maximal work rate. No statistical difference has been established. 